\title{
ANALYSIS OF STRESS AND STRAIN IN THE REINFORCED CONCRETE STRUCTURE OF A SPORTS HALL GRANSTAND
}

\author{
Diana Šimić, Ph.D.(Civ.Eng) \\ Faculty of Civil Engineering, University of Zagreb, Kačićeva 26, 10000 Zagreb, Croatia \\ Marina Frančić, M.Eng. (Civ.Eng.) \\ Faculty of Civil Engineering, University of Zagreb, Kačićeva 26, 10000 Zagreb, Croatia
}

\begin{abstract}
The analysis of stress and strain in the reinforced concrete structure of a sports hall grandstand was conducted theoretically, by means of the finite element method, and experimentally, by structural model testing in laboratory. Structural model for laboratory testing was prepared on the scale 1:10 using a medium density fibreboard plate $38 \mathrm{~mm}$ in thickness. Mechanical properties of the medium density fibreboard were determined by testing medium density fibreboard specimens in laboratory. After analysis of the reinforced concrete grandstand structure, and following comparison of results obtained by model testing in laboratory with results obtained by analysis via finite element method, it can be concluded that there is a good correspondence of research results for stress and deflection of the reinforced concrete grandstand structure.
\end{abstract}

Keywords: mechanical properties, stresses, resistance strain gauges, laboratory model, finite element method 


\section{Introduction}

In the calculation of stresses in structures certain assumptions are introduced, which may have a significant impact on the calculation results of stress in the structure, and therefore on level of safety of the structure. Structural analysis for a given structure is normally conducted using an idealized structural system, by which the actual behaviour of that structure is approximated $[1,2]$. This idealization of structural system reduces the accuracy of analysis of the stress and strain situation in structures, and leads to a situation in which the theoretical behaviour deviates from the actual behaviour of a structure.

The analysis of stress in reinforced concrete structure was conducted theoretically by the finite-element method (FEM) [3-5] and experimentally [6-8] by laboratory testing of a medium density fibreboard model in order to determine the real state of stress in RC structure.

The stress and strain situation in the reinforced concrete $(\mathrm{RC})$ frame structure of a sports hall grandstand, Figure 1, is considered in the paper. The span of the structure is $4.5 \mathrm{~m}$ and the total height is $9.5 \mathrm{~m}$. The structure is four times statically indeterminate. It is formed of two columns $2.7 \mathrm{~m}$ and $9.5 \mathrm{~m}$ in height, $38 / 38 \mathrm{~cm}$ in crosssection, and of a beam $4.85 \mathrm{~m}$ in length, $38 / 54 \mathrm{~cm}$ in cross-section. The columns are attached to the base, and the top edge of a higher column is supported against sliding. The beam and the column are rigidly connected to one another.

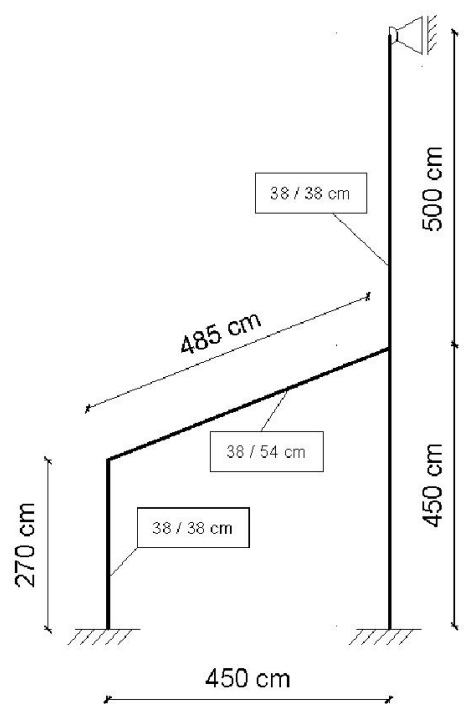

Figure 1 - Scheme of RC frame structure of a sports hall grandstand

The experimental testing of the structure was conducted on a medium density fibreboard scale model. Results obtained by experimental testing were compared with the results previously obtained by calculation based on dimensional analysis $[9,10]$ and FEM analysis.

\section{Determination of mechanical properties of medium density fibreboard}

The reinforced concrete structure model to be used in laboratory testing was made on the scale of 1:10 using the medium density fibreboard (MDF) plate $38 \mathrm{~mm}$ in thickness. Mechanical properties of the medium density fibreboard out of which the model was prepared were determined before the actual model testing. Medium density fibreboard specimens were tested using the ZWICK apparatus. Z600E is a universal compression-tension testing apparatus, $600 \mathrm{kN}$ in capacity, operated by electric traction. It is a state-of-the art and highly accurate laboratory testing apparatus. Tensile strength of the medium density fibreboard in the direction of fibres and opposite to the direction of fibres was determined by flexural strength testing on the specimen size $1 / \mathrm{b} / \mathrm{h}=$ $38 / 3.8 / 3.8 \mathrm{~cm}$ [11], Figure 2. 


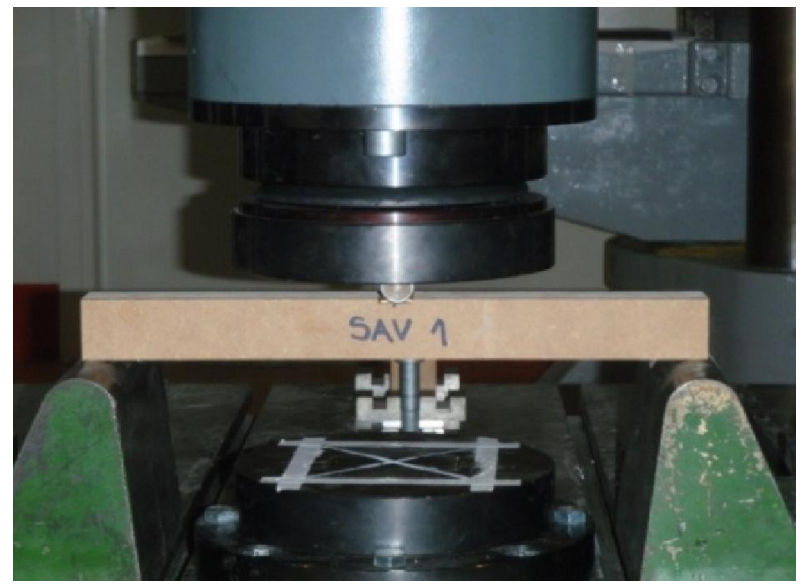

Figure 2 - Medium density fibreboard specimen subjected to flexural strength testing

The tensile strength data for the medium density fibreboard specimen subjected to flexural strength testing, in the direction parallel to fibres and perpendicular to fibres, are presented in Table 1.

Table 1 - Tensile strength of medium density fibreboard specimen subjected to flexural strength testing

\begin{tabular}{|c|c|c|c|c|c|c|}
\cline { 2 - 7 } \multicolumn{1}{c|}{} & \multicolumn{3}{c|}{ Load in the direction parallel to fibres } & \multicolumn{3}{c|}{ Load in the direction perpendicular to fibres } \\
\cline { 2 - 7 } \multicolumn{1}{c|}{} & Specimen 1 & Specimen 2 & Specimen3 & Specimen 4 & Specimen 5 & Specimen 6 \\
\hline$F_{\max }[\mathrm{kN}]$ & 2.43 & 2.71 & 2.63 & 2.32 & 2.04 & 2.25 \\
\hline$\sigma_{M}[\mathrm{MPa}]$ & 23.91 & 26.64 & 25.91 & 26.24 & 23.13 & 25.46 \\
\hline $\bar{\sigma}_{M}[\mathrm{MPa}]$ & \multicolumn{3}{|c|}{25.49} & \multicolumn{3}{c|}{24.94} \\
\hline
\end{tabular}

Based on the data given in Table 1, it can be concluded that tensile strength of the medium density fibreboard is almost identical at load applied parallel to fibres and at load applied perpendicular to fibres. Strain diagrams for specimens 1, 2, 3 with load applied parallel to fibres are presented in Figure 3. Strain diagrams for the specimens 4, 5, 6 with load applied perpendicular to fibres are presented in Figure 4.

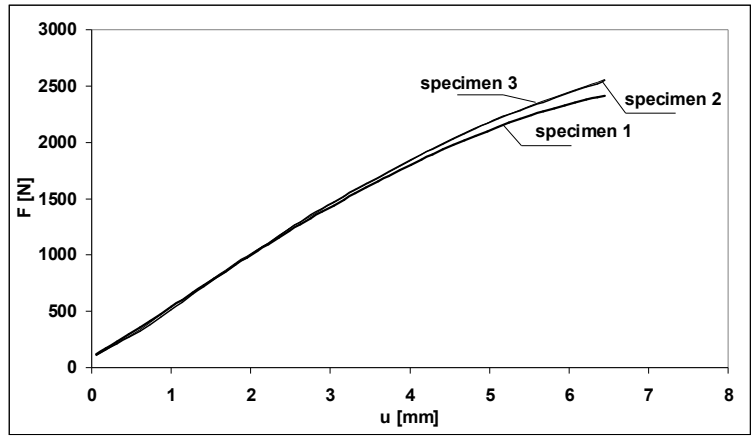

Figure 3 - Strain diagram for specimens 1, 2 and 3 with load applied parallel to fibres

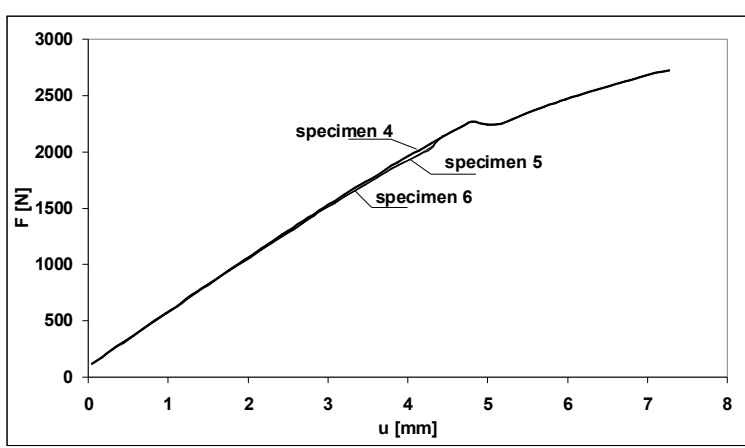

Figure 4 - Strain diagram for specimens 4, 5 and 6 with load applied perpendicular to fibres

Compressive strength of the medium density fibreboard plate subjected to load parallel to fibres was determined on prismatic specimens measuring $d / b / h=7.6 / 3.8 / 7.6 \mathrm{~cm}$, Figure 5 . 


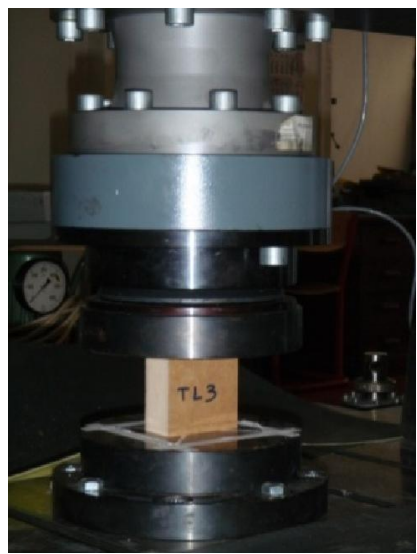

Figure 5 - Specimen subjected to compressive load parallel to fibres

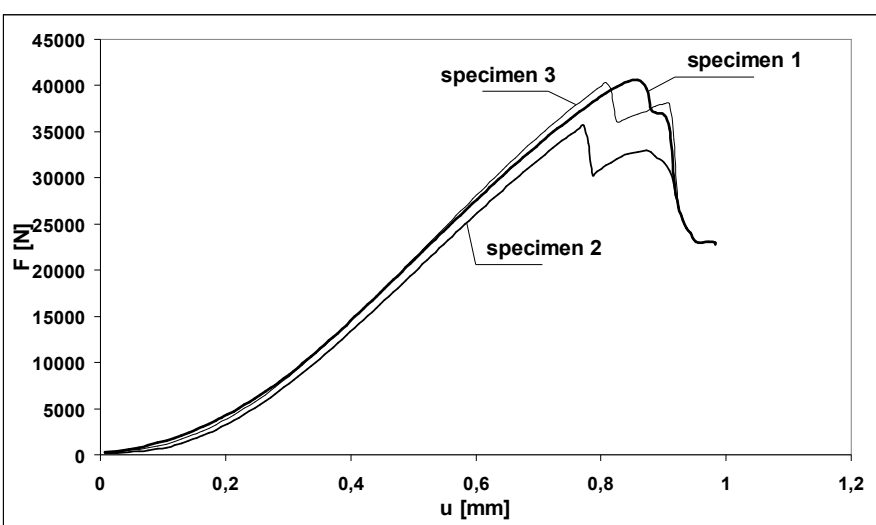

Figure 6 - Strain diagram for specimens 1, 2 and 3 at compressive load parallel to fibres

The data on compressive strength of the medium density fibreboard subjected to load parallel to fibres are shown in Table 2. The strain diagram for the specimens 1,2, 3 at compressive load parallel to fibres is shown in Figure 6. Compressive strength of the medium density fibreboard subjected to load perpendicular to fibres was determined on the specimens $4,5,6$ measuring $d / b / h=4 / 4 / 3.8 \mathrm{~cm}$, Figure 7 .

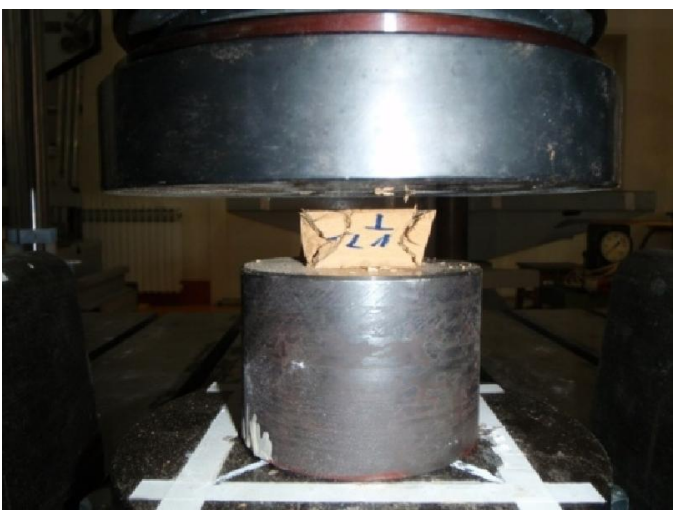

Figure 7 - Specimen subjected to compressive load perpendicular to fibres

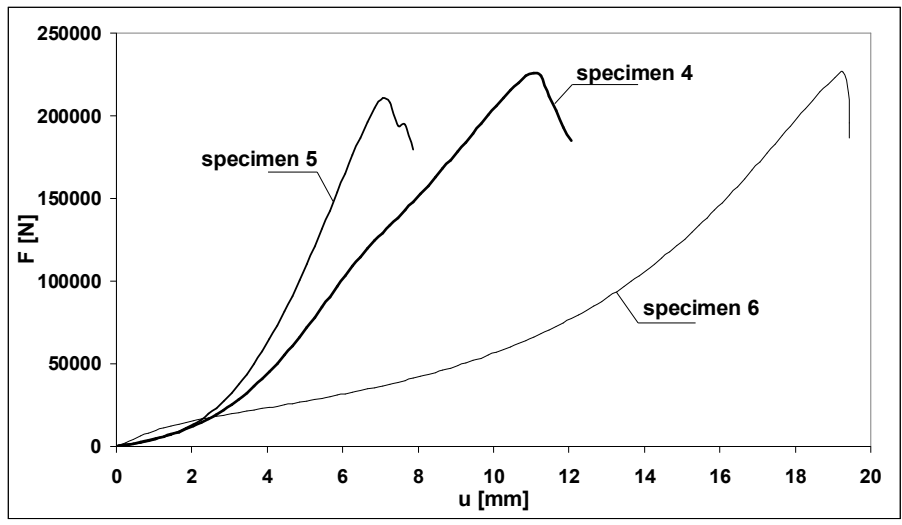

Figure 8 - Strain diagram for specimens 4,5 and 6 at compressive load perpendicular to fibres

The data on compressive strength of the medium density fibreboard subjected to load perpendicular to fibres are shown in Table 2. The strain diagram for the specimens 4, 5, 6 at compressive load perpendicular to fibres is shown in Figure 8.

Table 2 - Compressive strength of medium density fibreboard

\begin{tabular}{|c|c|c|c|c|c|c|}
\cline { 2 - 7 } \multicolumn{1}{c|}{} & \multicolumn{3}{c|}{ Compressive load parallel to fibres } & \multicolumn{3}{c|}{ Compressive load perpendicular to fibres } \\
\cline { 2 - 7 } \multicolumn{1}{c|}{} & Specimen 1 & Specimen 2 & Specimen 3 & Specimen 4 & Specimen 5 & Specimen 6 \\
\hline $\mathrm{F}_{\max }[\mathrm{kN}]$ & 40.7 & 35.9 & 39.1 & 228 & 214 & 227 \\
\hline$\sigma_{M}[\mathrm{MPa}]$ & 14.28 & 12.59 & 13.17 & 142.4 & 133.7 & 141.7 \\
\hline $\bar{\sigma}_{M}[\mathrm{MPa}]$ & \multicolumn{3}{|c|}{13.52} & \multicolumn{3}{c|}{139.3} \\
\hline
\end{tabular}


According to the test results shown in Table 2, it can be concluded that compressive strength of the medium density fibreboard subjected to compressive load perpendicular to fibres is 10 times greater than compressive strength at compressive load parallel to fibres. Elastic constants of the medium density fibreboard, elastic modulus $E$ and Poisson ratio $v$ were determined on two prismatic specimens measuring $\mathrm{d} / \mathrm{b} / \mathrm{h}=7.6 / 3.8 / 22.8 \mathrm{~cm}$ at compressive load parallel to fibres. Strain was measured on prismatic specimens using resistance strain gauges, Figure 9.

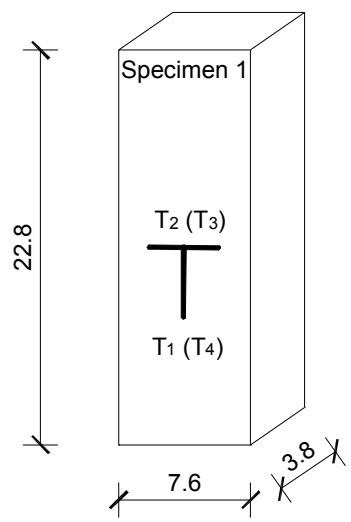

a)

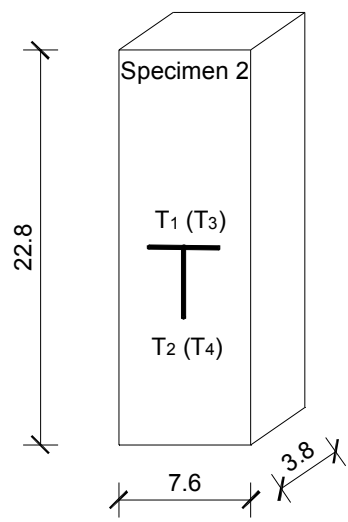

Figure 9 - a) MDF specimens with resistance strain gauges in position, b) specimen 2 in testing machine during compressive strength testing parallel to fibres

Four resistance strain gauges were attached to the specimen 1: at the front side parallel to fibres $T_{1}$ and perpendicular to fibres $T_{2}$, and at the back side parallel to fibres $T_{4}$ and perpendicular to fibres $T_{3}$. Four resistance strain gauges were attached to the specimen 2: at the front side parallel to fibres $T_{2}$ and perpendicular to fibres $T_{1}$, and at the back side parallel to fibres $T_{4}$ and perpendicular to fibres $T_{3}$. The specimen 2 in the testing machine, subjected to compressive force parallel to fibres, is shown in Figure $9 \mathrm{~b}$. Test results for specimens 1 and 2 are presented in Tables 3 and 4, respectively.

Table 3 - Determination of elastic modulus and Poisson ratio on specimen 1

\begin{tabular}{|c|c|c|c|c|c|c|c|c|c|}
\hline $\begin{array}{l}\text { Loading } \\
\text { phases }\end{array}$ & $\mathrm{F}_{\max }[\mathrm{kN}]$ & $\begin{array}{c}\varepsilon 1 \\
{[\mu \mathrm{m} / \mathrm{m}]}\end{array}$ & $\begin{array}{c}\varepsilon_{2} \\
{[\mu \mathrm{m} / \mathrm{m}]}\end{array}$ & $\begin{array}{c}\varepsilon_{3} \\
{[\mu \mathrm{m} / \mathrm{m}]}\end{array}$ & $\begin{array}{c}\varepsilon 4 \\
{[\mu \mathrm{m} / \mathrm{m}]}\end{array}$ & $\begin{array}{c}E^{\prime \prime}[\mathrm{MPa}] \\
\text { (for T1) }\end{array}$ & $\begin{array}{l}E^{\prime \prime}[\mathrm{MPa}] \\
\text { (for T4) }\end{array}$ & $\begin{array}{c}v \\
\left(\varepsilon_{1} / \varepsilon_{2}\right)\end{array}$ & $\begin{array}{c}v \\
\left(\varepsilon_{3} / \varepsilon_{4}\right)\end{array}$ \\
\hline I & 14.55 & -2231 & 518 & 435 & -1788 & 2258 & 2818 & 0.23 & 0.24 \\
\hline II & 14.60 & -2204 & 515 & 438 & -1801 & 2294 & 2807 & 0.23 & 0.24 \\
\hline III & 14.61 & -2201 & 505 & 437 & $\begin{array}{l}-1841 \\
\end{array}$ & 2298 & 2748 & 0.23 & 0.24 \\
\hline IV & 14.63 & -2170 & 505 & 438 & -1844 & 2334 & 2747 & 0.23 & 0.24 \\
\hline & & & & & & \multicolumn{2}{|c|}{$\bar{E}^{\prime \prime}[\mathrm{MPa}]$} & \multicolumn{2}{|c|}{$\bar{v}$} \\
\hline & & & & & & 2296 & 2780 & \multicolumn{2}{|c|}{0.235} \\
\hline
\end{tabular}

Table 4 - Determination of elastic modulus and Poisson ratio on specimen 2

\begin{tabular}{|c|c|c|c|c|c|c|c|c|}
\hline $\begin{array}{l}\text { Loading } \\
\text { phases }\end{array}$ & $F_{\max }[\mathrm{kN}]$ & $\begin{array}{c}\varepsilon_{1} \\
{[\mu \mathrm{m} / \mathrm{m}]}\end{array}$ & $\begin{array}{c}\varepsilon_{2} \\
{[\mu \mathrm{m} / \mathrm{m}]}\end{array}$ & $\begin{array}{c}\varepsilon_{3} \\
{[\mu \mathrm{m} / \mathrm{m}]}\end{array}$ & $\begin{array}{c}\varepsilon_{4} \\
{[\mu \mathrm{m} / \mathrm{m}]}\end{array}$ & $\begin{array}{c}E^{\prime \prime}[\mathrm{MPa}] \\
\text { (for T2) }\end{array}$ & $\begin{array}{c}E^{\prime[}[\mathrm{MPa}] \\
\text { (for T4) }\end{array}$ & $\begin{array}{c}v \\
\left(\varepsilon_{3} / \varepsilon_{4}\right)\end{array}$ \\
\hline 1 & 14.58 & 3 & -1813 & 541 & -1775 & 2785 & 2844 & 0.30 \\
\hline II & 14.43 & 12 & -1806 & 550 & -1752 & 2767 & 2852 & 0.31 \\
\hline III & 14.62 & 4 & -1819 & 544 & -1765 & 2783 & 2868 & 0.31 \\
\hline IV & 14.70 & 10 & -1710 & 595 & -1835 & 2977 & 2774 & 0.31 \\
\hline & & & & & & \multicolumn{2}{|c|}{$\bar{E}^{\prime \prime}[\mathrm{MPa}]$} & $\bar{v}$ \\
\hline
\end{tabular}


The mean values of elastic modulus $\bar{E}^{\prime \prime}=2685 \mathrm{MPa} \approx 2.7 \mathrm{GPa}$ and Poisson ratio $\bar{v}=0.26$ for the medium density fibreboard were calculated using data presented in Tables 3 and 4.

\section{Laboratory testing of grandstand model}

The model of the reinforced concrete grandstand structure, as needed for laboratory testing [12-14], was made of the medium density fibreboard on the scale of 1:10, Figure 10. The model was built in a single piece out of the medium density fibreboard plate $38 \mathrm{~mm}$ in thickness. Three steps were subsequently glued on to the beam to facilitate application of load during grandstand model testing.

The model with resistance strain gauges for deformation measurements, and with inductive strain gauges for displacement measurements $[15,16]$, ready for testing, is presented in Figure 10b. The distribution of measurement points along the model is shown in Figure 11.

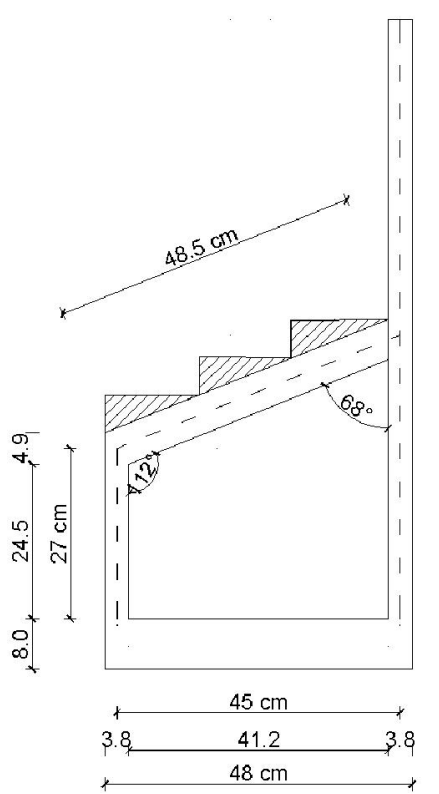

a)

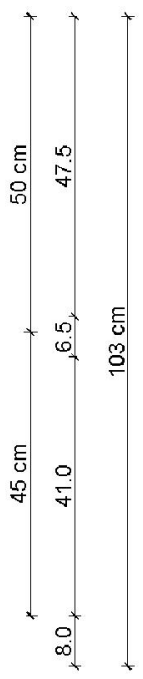

gauges, ready for testing

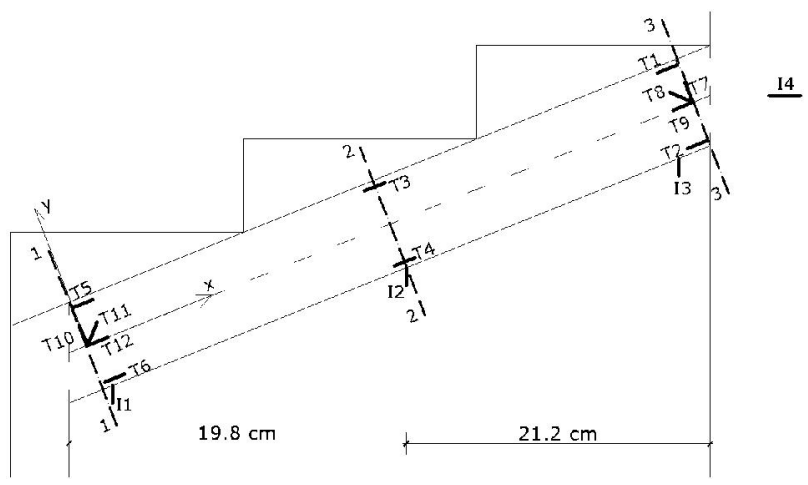

Figure 11 - Disposition of resistance strain gauges ("T") for strain measurements, and inductive strain gauges ("I") for displacement measurements, along the grandstand girder 
Grandstand structure model testing was conducted in four loading phases, during which load was increased in each subsequent phase. In each phase, load was maintained for a specified time interval, i.e. until stabilization of strain values on the readout device. After that, the weight was removed from the model and the testing resumed with the second phase, at a higher load. The total load applied to model amounted to $300 \mathrm{~N}$ in the first phase, Figure 12a, $600 \mathrm{~N}$ in the second phase, Figure 12b, $1050 \mathrm{~N}$ in the third phase, Figure 12c, and $2190 \mathrm{~N}$ in the fourth phase, Figure $12 \mathrm{~d}$.

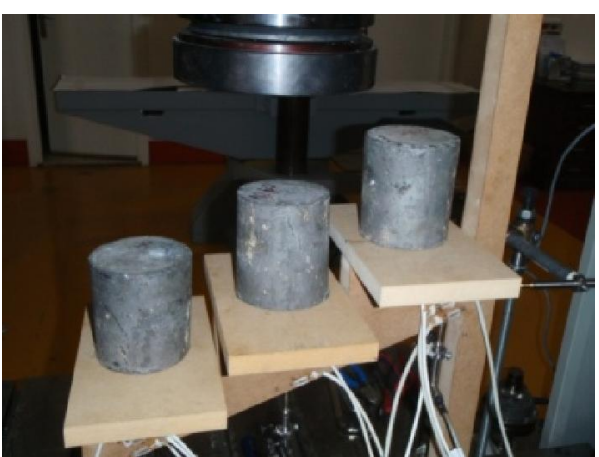

a)

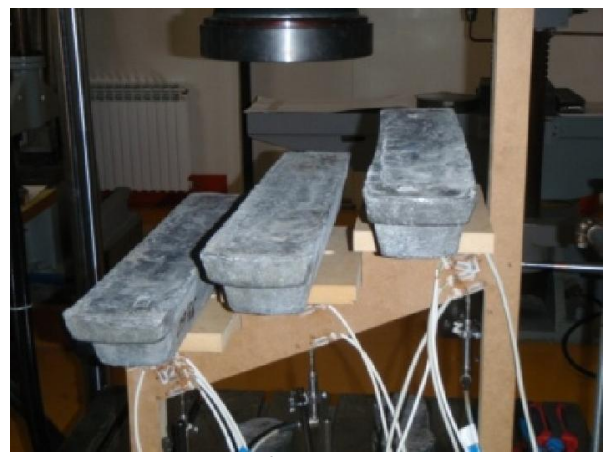

c)

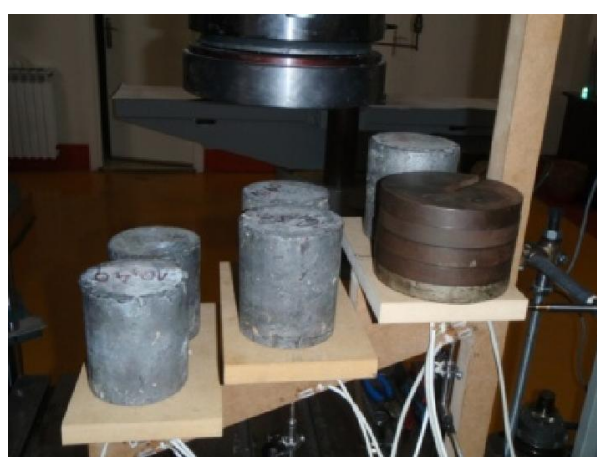

b)

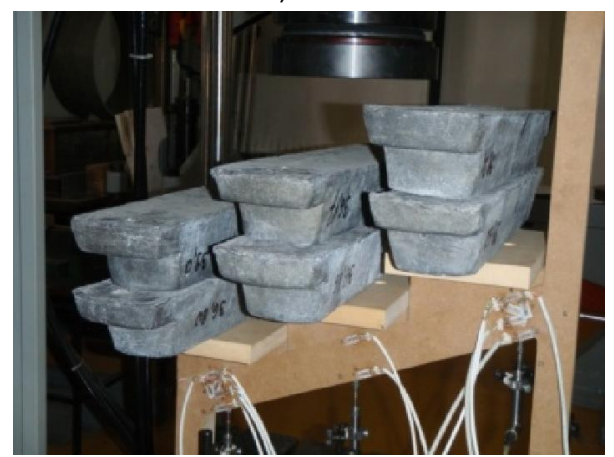

d)

Figure 12 - Model loading phases: a) Phase 1, b) Phase 2, c) Phase 3, d) Phase 4

The test results in form of strain diagrams are presented in Figure 13. Strain values were measured at the measurement points $T_{3}$ and $T_{4}$, which are situated at points subjected to maximum stress. Displacements were measured at four measurement points using inductive strain gauges, Figure 11. Displacement diagrams with measurement points $I_{1}, l_{2}, I_{3}, I_{4}$ are presented in Figure 14.

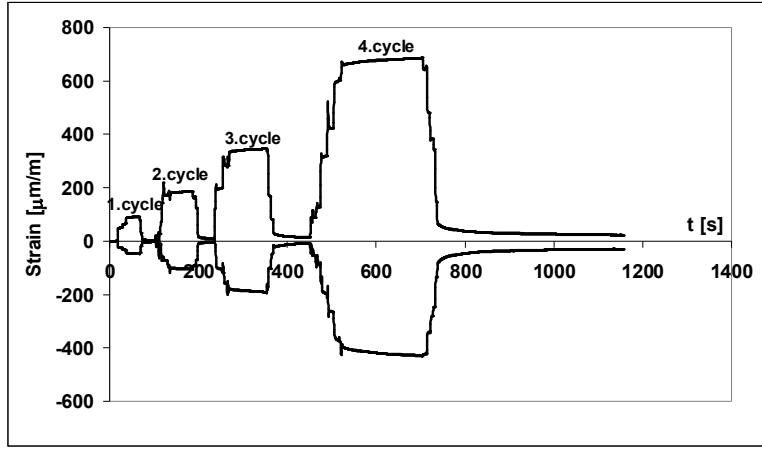

Figure 13 -Strain diagram with values $\left(T_{3}\right.$ and $\left.T_{4}\right)$

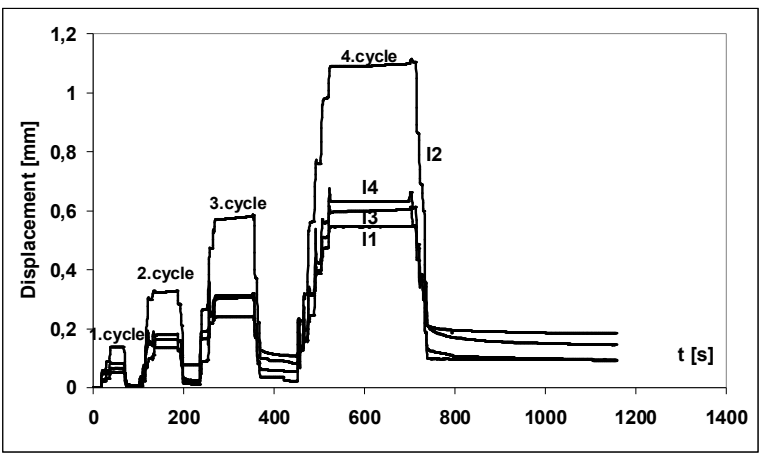

Figure 14 - Displacement diagram $\left(I_{1}, I_{2}, I_{3}, I_{4}\right)$

The rosette formed of resistance strain gauges $T_{10}, T_{11} i T_{12}$ is marked as the measurement point $R_{2}$. Due to breakdown at resistance strain gauge $T_{7}$, the measurement points $T_{7}, T_{8} i T_{9}$, forming the rosette marked as $R_{1}$, 
were not included in the subsequent analysis. The uniaxial stress was determined at the measurement points $T_{1}$, $T_{2}, T_{3}, T_{4}, T_{5}$ and $T_{6}$ using the Hooke's law by applying the previously defined elastic modulus $E=2700 \mathrm{MPa}$. Plane stress/strain was determined at the measurement point $R_{2}\left(T_{10}, T_{11}, T_{12}\right)$. Here the stress values $\sigma_{x}$ and $\tau_{x y}$ were determined (the axis $x$ corresponds to the beam axis, while the axis $y$ is perpendicular to the beam axis). Stress values for all four loading phases are presented in Table 5.The data on displacement registered in measurement points $I_{1}, l_{2}, l_{3}, l_{4}$ are presented in Table 6 .

Table 5 - Stress values registered at measurement points $T_{1}-T_{6}$ and $R_{2}$

\begin{tabular}{|c|c|c|c|c|c|c|c|c|}
\hline \multicolumn{9}{|c|}{ Stress values $\sigma[\mathrm{MPa}]$} \\
\hline \multirow{2}{*}{ Loading phases } & \multirow{2}{*}{$\mathrm{T} 1$} & \multirow{2}{*}{$\mathrm{T} 2$} & \multirow{2}{*}{ T3 } & \multirow{2}{*}{$\mathrm{T} 4$} & \multirow{2}{*}{ T5 } & \multirow{2}{*}{ T6 } & \multicolumn{2}{|c|}{ R2 } \\
\hline & & & & & & & $\sigma_{x}$ & $\tau_{x y}$ \\
\hline $\mathrm{I}$ & 0.0545 & -0.0670 & -0.1264 & 0.2454 & -0.0189 & -0.0197 & -0.0108 & -0.0334 \\
\hline II & 0.1299 & -0.1080 & -0.2824 & 0.4995 & -0.0327 & -0.0203 & -0.0309 & -0.0836 \\
\hline III & 0.2568 & -0.2117 & -0.5206 & 0.9329 & -0.0680 & -0.0311 & -0.0765 & -0.1702 \\
\hline IV & 0.5187 & -0.4833 & -1.1429 & 1.8495 & -0.1407 & -0.0699 & -0.1066 & -0.3167 \\
\hline
\end{tabular}

Table 6 - Displacement values registered at measurement points $I_{1}, I_{2}, I_{3}, I_{4}$

\begin{tabular}{|c|c|c|c|c|}
\hline \multicolumn{5}{|c|}{ Displacement values $u[\mathrm{~mm}]$} \\
\hline Loading phases & I1 & I2 & I3 & 14 \\
\hline I & 0.053 & 0.137 & 0.064 & 0.084 \\
\hline II & 0.136 & 0.327 & 0.163 & 0.180 \\
\hline III & 0.210 & 0.578 & 0.283 & 0.305 \\
\hline IV & 0.435 & 1.100 & 0.544 & 0.546 \\
\hline
\end{tabular}

\section{Computation of grandstand structure model}

The grandstand structure 1:10 scale model, previously tested in laboratory, was analyzed using the software program package SAP2000 [17]. The model was formed using plate elements so that steps, glued to the model, and enabling easier application of load during model testing, can also be taken into account. The following mechanical properties were defined in the model: elastic modulus $E=2700 \mathrm{Mpa}$ and Poisson ratio $v=0.26$. The finite element network [18-19] is presented in Figure 15. Network density is higher in the zone of the analyzed points. Figure 16 shows four model loading phases, which correspond to model loading phases during model testing in laboratory.

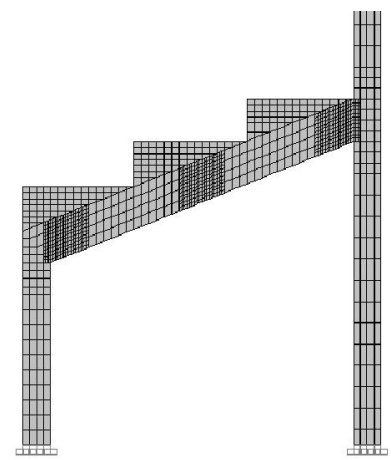

Figure 15 - Finite element network

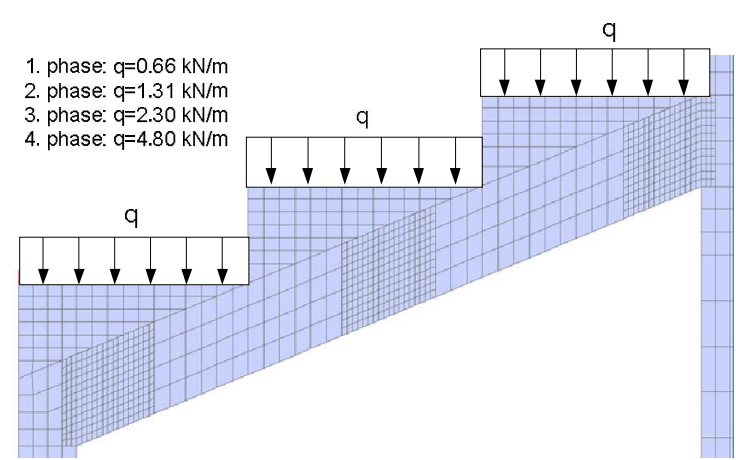

Figure 16 - Scheme of model loading phases 


\section{Comparison of computation and model testing results}

Comparison of the stress results in the first phase of loading is presented in Table 7, and comparison of the displacement results is given in Table 8.

Table 7 - Comparison of stress results in the 1stloading phase

\begin{tabular}{|c|c|c|c|c|c|c|c|c|}
\hline \multicolumn{19}{|c|}{ Stress $\sigma[\mathrm{MPa}]$} \\
\hline & \multirow{2}{*}{ T1 } & T2 & T3 & T4 & T5 & T6 & \multicolumn{2}{|c|}{ R2 } \\
\cline { 5 - 9 } & & & & & & & $\sigma_{x}$ & $\tau_{x y}$ \\
\hline Testing & 0.0545 & -0.0670 & -0.1264 & 0.2454 & -0.1890 & -0.0197 & -0.0108 & -0.0334 \\
\hline Computation & 0.0457 & -0.0640 & -0.1107 & 0.2515 & -0.0172 & -0.0197 & -0.0126 & -0.0489 \\
\hline Differenœ[\%] & $16 \%$ & $4 \%$ & $7 \%$ & $2 \%$ & $9 \%$ & $0 \%$ & $14 \%$ & $31 \%$ \\
\hline
\end{tabular}

Table 8 - Comparison of displacement results in the $1^{\text {st }}$ loading phase

\begin{tabular}{|c|c|c|c|c|}
\hline \multicolumn{5}{|c|}{ Displacement $u[\mathrm{~mm}]$} \\
\hline & $\mathrm{I} 1$ & $\mathrm{I} 2$ & $\mathrm{I} 3$ & $\mathrm{I}$ \\
\hline Testing & 0.053 & 0.137 & 0.064 & 0.084 \\
\hline Computation & 0.053 & 0.153 & 0.061 & 0.093 \\
\hline Difference[\%] & $0 \%$ & $10 \%$ & $5 \%$ & $10 \%$ \\
\hline
\end{tabular}

Comparison of the stress results in the second loading phase is presented in Table 9, and comparison of the displacement results is given in Table 10.

Table 9 - Comparison of stress results in the $2^{\text {nd }}$ loading phase

\begin{tabular}{|c|c|c|c|c|c|c|c|c|}
\hline \multicolumn{9}{|c|}{ Stress $\sigma[\mathrm{MPa}]$} \\
\hline & \multirow{2}{*}{$\mathrm{T} 1$} & T2 & T3 & T4 & \multirow{2}{*}{ T5 } & T6 & \multicolumn{2}{|c|}{ R2 } \\
\cline { 6 - 9 } & & & & & & & $\sigma_{x}$ & $\tau_{x y}$ \\
\hline Testing & 0.1299 & -0.1080 & -0.2824 & 0.4995 & -0.0327 & -0.0203 & -0.0309 & -0.0836 \\
\hline Computation & 0.0972 & -0.1308 & -0.2257 & 0.5018 & -0.0347 & -0.0193 & -0.0332 & -0.1202 \\
\hline Differenœ[\%] & $25 \%$ & $17 \%$ & $20 \%$ & $1 \%$ & $6 \%$ & $5 \%$ & $7 \%$ & $30 \%$ \\
\hline
\end{tabular}

Table 10 - Comparison of displacement results in the $2^{\text {nd }}$ loading phase

\begin{tabular}{|c|c|c|c|c|}
\hline \multicolumn{5}{|c|}{ Displacement $u[\mathrm{~mm}]$} \\
\hline & 11 & 12 & 13 & 14 \\
\hline Testing & 0.136 & 0.327 & 0.163 & 0.180 \\
\hline Computation & 0.112 & 0.307 & 0.122 & 0.186 \\
\hline Difference[\%] & $18 \%$ & $6 \%$ & $25 \%$ & $3 \%$ \\
\hline
\end{tabular}

Comparison of the stress results in the third loading phase is presented in Table 11, and comparison of the displacement results is given in Table 12 . 
Table 11 - Comparison of stress results in the $3^{\text {rd loading phase }}$

\begin{tabular}{|c|c|c|c|c|c|c|c|c|}
\hline \multicolumn{1}{|c|}{ Stress $\sigma[\mathrm{MPa}]$} \\
\hline & \multirow{2}{*}{ T1 } & T2 & T3 & T4 & T5 & T6 & \multicolumn{2}{|c|}{ R2 } \\
\cline { 6 - 9 } & & & & & & & $\sigma_{x}$ & $\tau_{x y}$ \\
\hline Testing & 0.2568 & -0.2117 & -0.5206 & 0.9329 & -0.0680 & -0.0311 & -0.0765 & -0.1702 \\
\hline Computation & 0.1725 & -0.2179 & -0.4218 & 0.8897 & -0.0562 & -0.0340 & -0.0587 & -0.2088 \\
\hline Differenœ[\%] & $32 \%$ & $3 \%$ & $19 \%$ & $5 \%$ & $17 \%$ & $9 \%$ & $23 \%$ & $18 \%$ \\
\hline
\end{tabular}

Table 12 - Comparison of displacement results in the $3^{\text {rd }}$ loading phase

\begin{tabular}{|c|c|c|c|c|}
\hline \multicolumn{5}{|c|}{ Displacement $u[\mathrm{~mm}]$} \\
\hline & $\mathrm{I} 1$ & $\mathrm{I}$ & $\mathrm{I}$ & $\mathrm{I}$ \\
\hline Testing & 0.210 & 0.578 & 0.283 & 0.305 \\
\hline Computation & 0.177 & 0.543 & 0.214 & 0.328 \\
\hline Differenœ[\%] & $16 \%$ & $6 \%$ & $24 \%$ & $7 \%$ \\
\hline
\end{tabular}

Comparison of the stress results in the 4thloading phase is presented in Table 13 , and comparison of the displacement results is given in Table 14 .

Table 13 -Comparison of stress results in the $4^{\text {th }}$ loading phase

\begin{tabular}{|c|c|c|c|c|c|c|c|c|}
\hline \multicolumn{1}{|c|}{ Stress $\sigma[\mathrm{MPa}]$} \\
\hline & \multirow{2}{*}{$\mathrm{T} 1$} & T2 & T3 & T4 & T5 & \multirow{2}{*}{ T6 } & \multicolumn{2}{|c|}{ R2 } \\
\cline { 6 - 9 } & & & & & & & $\sigma_{x}$ & $\tau_{x y}$ \\
\hline Testing & 0,5187 & $-0,4833$ & $-1,1429$ & 1,8495 & $-0,1407$ & $-0,0699$ & -0.1066 & -0.3167 \\
\hline Computation & 0,3403 & $-0,4088$ & $-0,8800$ & 1,8209 & $-0,1274$ & $-0,0712$ & $-0,1210$ & $-0,4410$ \\
\hline Difference[\%] & $34 \%$ & $15 \%$ & $23 \%$ & $2 \%$ & $9 \%$ & $2 \%$ & $12 \%$ & $28 \%$ \\
\hline
\end{tabular}

Table 14 -Comparison of displacement results in the $4^{\text {th }}$ loading phase

\begin{tabular}{|c|c|c|c|c|}
\hline \multicolumn{5}{|c|}{ Displacement $u[\mathrm{~mm}]$} \\
\hline & $\mathrm{I} 1$ & $\mathrm{I} 2$ & $\mathrm{I} 3$ & 14 \\
\hline Testing & 0.435 & 1.100 & 0.544 & 0.546 \\
\hline Computation & 0.363 & 1.120 & 0.447 & 0.679 \\
\hline Difference[\%] & $17 \%$ & $2 \%$ & $18 \%$ & $19 \%$ \\
\hline
\end{tabular}

Graphical comparison of the stress results in the 4thloading phase is presented in Figure $17 \mathrm{a}, \mathrm{b}, \mathrm{c}$. 


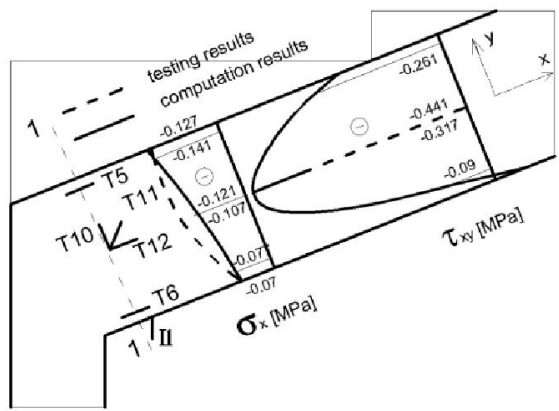

a)

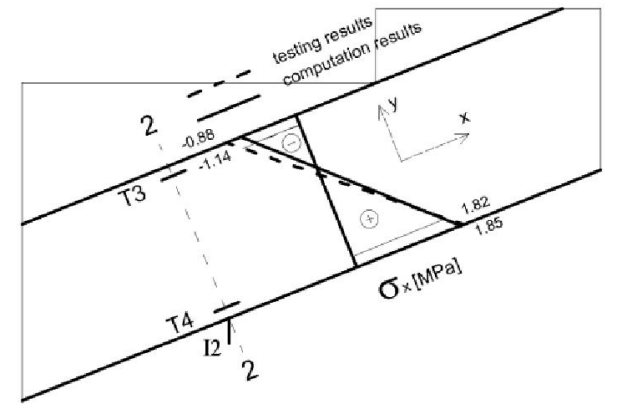

b)

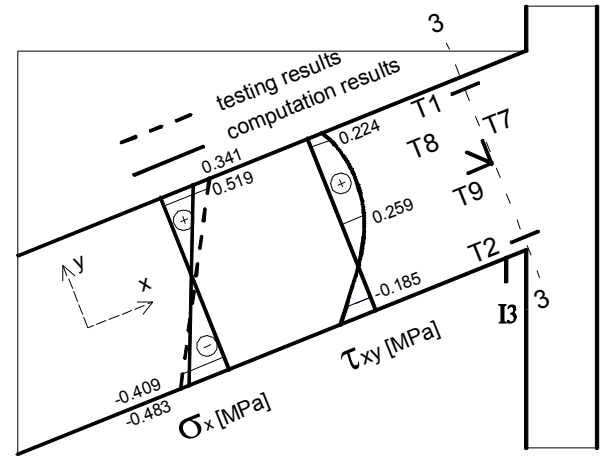

c)

Figure 17 - Stress diagrams: a) in cross-section 1-1, b) in cross-section 2-2, c) in cross-section 3-3

Figure 18 shows the load-stress diagram in the mid-span at the measurement point $T_{4}$ obtained by model testing for all four loading phases. Figure 19 shows the load-displacement diagram in the mid-span at the measurement point $\mathrm{I}_{2}$ obtained by model testing for all four loading phases.

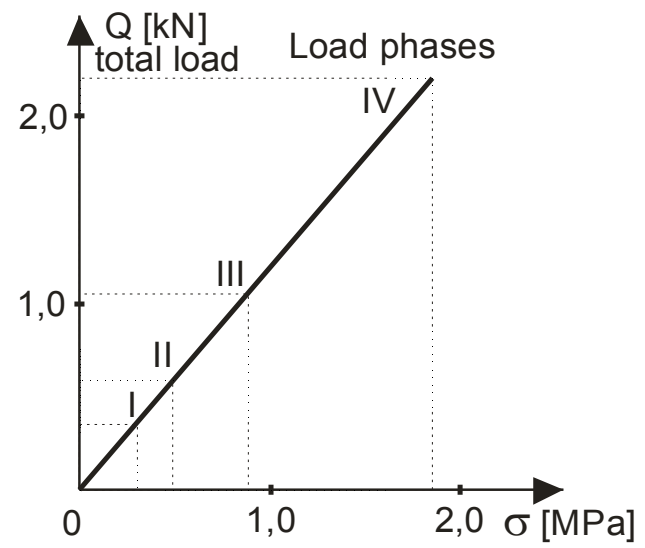

Figure18 - Load-stress diagram in midspan at measurement point $\mathrm{T}_{4}$

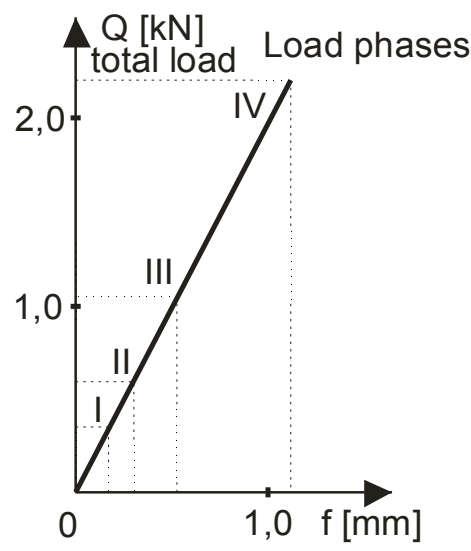

Figure 19 - Load-displacement diagram in midspan at measurement point $\mathrm{l}_{2}$

Linear dependence of load-stress and load-displacement was obtained for all four loading phases by laboratory testing. 


\section{Computation model for real structure}

The reinforced concrete frame structure of the grandstand measures $4.5 \mathrm{~m}$ in span, and $9.5 \mathrm{~m}$ in height. It is composed of two columns $38 / 38 \mathrm{~cm}$ in cross section, and of a beam $38 / 54 \mathrm{~cm}$ in cross-section. Grandstand steps are added to the model so that its shape resembles that of the model built in laboratory, Figure 20.

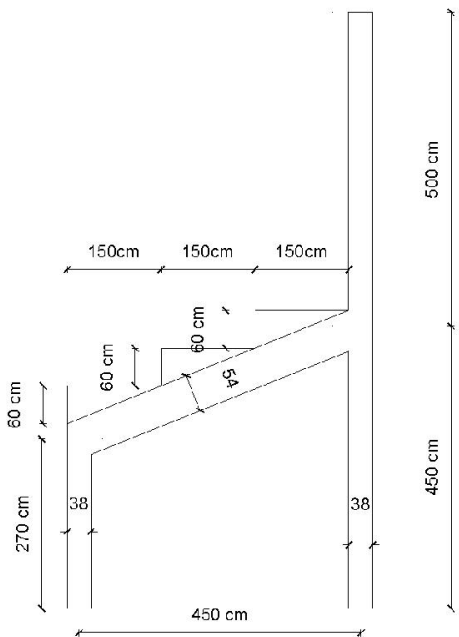

Figure 20 - Scheme of the RC finite grandstand structure with steps

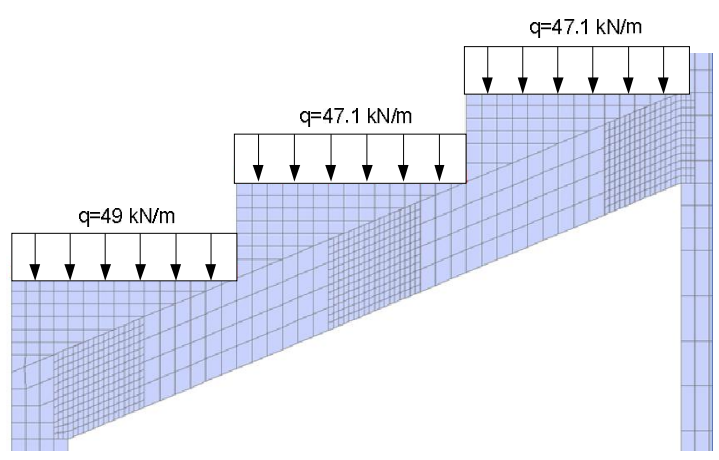

Figure 21 - Scheme of the fourth loading phase and an element network of the RC structure with steps

The relationship between loads, stresses and displacements of the laboratory model and of structure prototype is defined by the dimensional analysis $[9,10]$. The laboratory model of the structure, scaled 1:10, was prepared using the medium density fibreboard, and the scaling factor is:

$$
K_{I}=\frac{L_{m}}{L_{p}}=\frac{1}{10}
$$

The stress relationship between the laboratory model and the structure prototype is:

$$
K_{\sigma}=\frac{\sigma_{m}}{\sigma_{p}}=1
$$

The scale for load is:

$$
K_{F}=K_{\sigma} \cdot K_{l}^{2}=1 \cdot \frac{1}{100}=\frac{1}{100}
$$

Consequently, load acting on the laboratory model must be hundred times greater than those obtained by the analysis of the structure prototype.

The model of the structure was prepared in the program package SAP 2000. The elastic modulus of concrete $E_{b}=3 \cdot 10^{4} \mathrm{MPa}$ was adopted. The finite element network is similar to that of the $1: 10$ scale model tested in laboratory. To obtain a similar state of stress for the reinforced concrete structure and the model, the reinforced concrete structure should be subjected - according to dimensional analysis - to the load that is 100 times greater than the load applied on the model. At that load level of the reinforced concrete structure, the ratio of model to reinforced concrete structure deflections is 10/9. Test results were compared for the fourth loading phase in which the greatest (and hence the most relevant) load was applied. The reinforced concrete structure was subjected to total load of $219.0 \mathrm{kN}$ which is one hundred times greater than the load exerted on the model $2.19 \mathrm{kN}$. The loading scheme and finite element network on the reinforced concrete structure is shown in Figure 21. The comparison of stress values at the measurement points, as obtained by model testing and RC structure computation, is presented in Table 15. The comparison of displacement obtained by model testing and RC structure computation is presented in Table 16. 
Table 15 - Comparison of stress results

\begin{tabular}{|c|c|c|c|c|c|c|c|c|}
\hline \multicolumn{2}{|c|}{ Stress $\sigma[\mathrm{MPa}]$} \\
\hline & \multirow{2}{*}{$\mathrm{T} 1$} & T2 & T3 & T4 & T5 & T6 & \multicolumn{2}{|c|}{ R2 } \\
\cline { 7 - 9 } & & & & & & & $\sigma_{x}$ & $\tau_{x y}$ \\
\hline Testing & 0.5187 & -0.4833 & -1.1429 & 1.8495 & -0.1407 & -0.0699 & -0.1066 & -0.3167 \\
\hline Computation & 0.3410 & -0.3940 & -0.8440 & 1.7240 & -0.1360 & -0.0770 & -0.0970 & -0.4270 \\
\hline Differenœ[\%] & $34 \%$ & $18 \%$ & $26 \%$ & $7 \%$ & $3 \%$ & $9 \%$ & $9 \%$ & $26 \%$ \\
\hline
\end{tabular}

\section{Table 16 -Comparison of displacement results}

\begin{tabular}{|c|c|c|c|c|}
\hline \multicolumn{5}{|c|}{ Displacement $u[\mathrm{~mm}]$} \\
\hline & $\mathrm{I} 1$ & $\mathrm{I} 2$ & $\mathrm{I} 3$ & 14 \\
\hline Testing & 0.435 & 1.100 & 0.544 & 0.546 \\
\hline Computation & 0.398 & 0.993 & 0.470 & 0.600 \\
\hline Differenœ[\%] & $9 \%$ & $10 \%$ & $14 \%$ & $9 \%$ \\
\hline
\end{tabular}

The stress diagrams at sections 1-1, 2-2, and 3-3, as obtained by model testing and RC grandstand structure computation, are presented in Figures $22 \mathrm{a}, \mathrm{b}$, and $\mathrm{c}$.

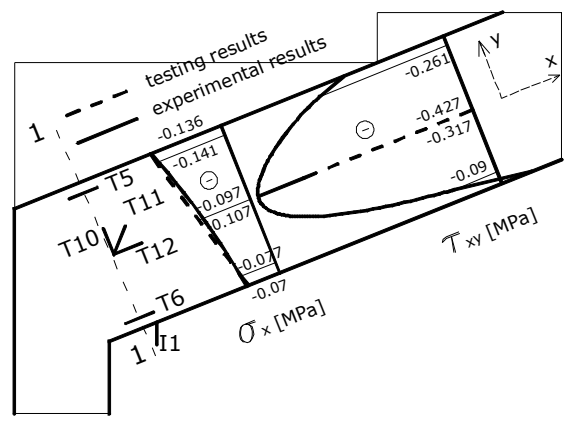

a)

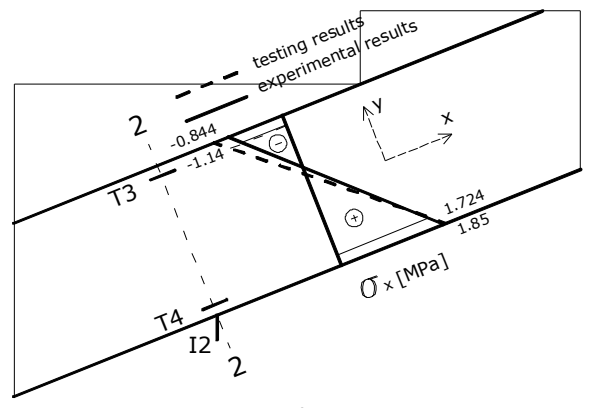

b)

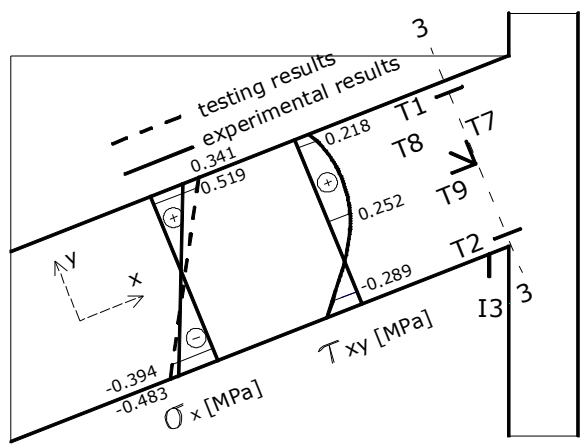

c)

Figure 22 - Stress diagrams: a) at cross-section 1-1, b) at cross-section 2-2, c) at cross-section 3-3 


\section{Conclusion}

The 1:10 scale model of the RC grandstand structure, designed for laboratory testing, was made of the medium density fibreboard plate $38 \mathrm{~mm}$ in thickness. Model testing was conducted in four loading phases, and load was increased in each subsequent phase. The comparison between the results obtained by laboratory model testing and model computation results by finite element method was conducted for each model loading phase. Somewhat bigger differences are noted at the upper zone (measuring points T1, T3 and T5) which can be explained by the fact that "steps" were glued to the central piece of the laboratory model unlike the FEM model which was monolithic.

To obtain a similar state of stress in the RC grandstand structure and on the model, the reinforced concrete structure had to be subjected - according to dimensional analysis - to load that is 100 times greater than load applied on the model. The computation of the RC grandstand structure was conducted using the finite element method for load corresponding to the fourth phase of model loading, in which load was the greatest, with the linear dependence between load and stress, and between load and displacement.

Based on the analysis and comparison of the laboratory model testing results with model computation results for all four loading phases, and according to comparison with the results obtained by computation of the $\mathrm{RC}$ grandstand structure, it can be concluded that there is a good correspondence between the experimental and theoretical results for stress and displacement of the RC grandstand structure. The results, obtained from FEM model analysis (Table 13 - computation) and the real structure FEM model (Table15 - computation), are compared and show a very good correspondence. It would be interesting, in some future analysis, to create an adequate monolithic laboratory model and compare these results to the existing ones.

\section{Literature}

[1] Ikubovskij, B. V.; Ermolaev, N. N.; Akridin, D. V. 1965. Ispitanie železobetonskih konstrukcij i soruženij, Izdateljstvo Viša škola, Moskva

[2] Kobayashi, A. S. 1990. Handbook on Experimental Mechanics, Prentice-Hall, New Jersey

[3] Schueller, W. 2008. Building Support Structures, Analysis and Design with SAP2000 Software, Computer and Structures Inc., Berkeley

[4] Pahl, P. J.; Stein, E.; Wunderlich, W. 1987. Finite Elemente in der Baupraxis, Verlag von Wilhelm Ernest\&Sohn, Berlin

[5] Zienkiewicz, O. C. 1970. The Finite Element Method in Structural and Continuum Mechanics, McGrawHill, London

[6] Kobayashi, A. S. 1990. Eksperimentaljnaja mehanika I i II, Mir, Moskva

[7] Dally, J. W.; Riley, W. F. 1991. Experimental Stress Analysis, Mc.Graw-Hill, Inc. New York

[8] Holman, J. P. 1994. Experimental Methods for Engineers, McGraw-Hill, New York

[9] Pobedrya, B. E.; Georgievskii, D. V. 2006. On the Proof of the П-Theorem in Dimension Theory, Russian Journal of Mathematical Physics, Vol. 13, pp 431-437.

[10] Sonin, A. A. 2004. A generalization of the Pi-theorem and dimensional analysis, Proceedings of the National Academy of Sciences of the United States of America, Vol. 101, pp 8525-8526

[11] Ganev, S.; Gendron, G.; Cloutier, A.; Beauregard, R. 2005.Mechanical Properties of MDF as a Function of Density and Moisture Content, Wood and Fiber Science

[12] Luzhin, V.; Zlochevsky, A. B.; Gorbunov, A.; Volohov, V. A. 1987.Inspection and Testing of Civil Engineering Structures, Mir Publisher, Moscow

[13] Bungey, J.H.; Millard, S.G. 1996. Testing of Concrete in Structures, 3. Edition, Blackie Academic \& Professional, Glasgow

[14] Aničić, D. 2003. Ispitivanje konstrukcija, Građevinski fakultet Sveučilišta u Osijeku, Osijek

[15] Montero, W.; Farag, R.; Diaz, V.; Ramirez, M.; Boada, B. L. 2011. Uncertainties Associated with Strain Maeasuring Systems Using Resistance Strain Gauges, The Journal of Strain Analysis for Engineering Design, Vol. 46, pp 1-13

[16] Šimić, V. 2002. Otpornost materijala II, Školska knjiga, Zagreb 
[17] Sap 2000 Analysis Reference Manual, Computers and Structures, Inc., Berkeley

[18] Wriggers, P. 1988. Finite Elemente in der Baupraxis, Ernest \& Sohn, Darmstadt

[19] Huebner, K. H.; Dewhirst, D. L.; Smith, D. E.; Byrom, T. G. 2001. The finite element method for engineers, John Wiley\&Sons, New York 